\title{
A STEM Model Encouraging Post-Baccalaureate Pathways for First Generation, Underrepresented Undergraduates
}

\section{Mary Jo Parker}

Scholars Academy, University of Houston-Downtown,USA.

\begin{abstract}
The University of Houston-Downtown supports a STEM program, Scholars Academy (SA) within the College of Sciences and Technology dedicated to enhancing, preparing, and enlightening minority, underrepresented, and first-generation majors seeking entrance into workforce, graduate, and professional programs of preparation. Over the past 18 years the University of Houston-Downtown Scholars Academy has implemented a series of success components supporting the nurturance of post-baccalaureate graduate and professional pursuit yielding a 51\% acceptance rate into medical school, over 68 professional degrees (ranging from MD to DO to DDS and DPharm) earned by alumni, over 20 PhD degrees, and over 900 minority/underrepresented undergraduates moving into professional/graduate fields. Briefly, STEM success components consist of 1) Freshman Ramp Up support; 2) Academic Skill Monitoring; 3) Mentoring, peer to peer and PhD to undergraduate; 4) Career and Research Skill Development support; and finally 5) Leadership Development through Community Engagement support.
\end{abstract}

Keywords: undergraduate mentoring; research mentoring; facilitating beyond undergraduate graduation; facilitating post-baccalaureate clinical/medical degrees. 


\section{Introduction}

Why is a topic related to undergraduate pathways important to an international audience? Like all industries within the U.S. and many outside of the U.S., the current workforce is undergoing transformations of enormous consequence across the clinical, medical, graduate, and professional science communities of training and practice (Kotkin, 2010; Shrethra \& Heisler, 2011; Lerman \& Schmidt, nd). Examining how one undergraduate institution approaches the issue of invigorating and nurturing undergraduates to develop confidence and competence to envision themselves a part of the professional, clinical, medical, and workforce career-scape may provide insight to other undergraduate institutions seeking to build pathways to future graduate and professional careers (Lopatti, 2004, 2007).

Based on current demographics that Hispanics are soon to become the major ethnic group in Texas by 2030 (Associated Press, 2004) there is a need for Texas to close the science education gap, recruiting more Hispanic students and other minorities into university STEM degree programs. A clear need exists for more minority undergraduate students across a broad natural sciences, computer and mathematical sciences, and engineering technology degree emphasis to enroll in and complete STEM degrees, thus lessening an educational attainment gap evidenced among minorities. Similar data points can be generated for almost any of the 50 US states in 2018. The ultimate goal of increasing the pipeline of minority students entering into baccalaureate degrees and widening the pathway to include post-baccalaureate advanced degree study is related to the need for familiarity of the college experience, pre-college academic support, academic monitoring, mentoring by STEM faculty and undergraduates already successful in the STEM arena, broadened exposure to graduate and industry experts and opportunities, research and career exposure, and leadership development through STEM arenas.

Minority students continue to dismiss the four-year university out of fear of the unknown prior to entrance. Minorities, particularly minority women, continue to fail-out of first-year barrier STEM courses as a result of no substantive support services, lack of adequate precollege preparatory coursework, and/or little to no acculturation into the study hours and techniques needed to grasp rigorous STEM topics as presented in first year courses. First generation minority students, in particular, have no historical, familial connections to what the collegiate expectations are for STEM students, thus have the least supportive network available to them once entrance into the STEM degree curriculum begins. Understanding the issue enables solutions to arise. We believe the Scholars Academy program to be one of many solutions which enable the widening of the advanced degree study.

Established in 1999, the Scholars Academy as an academic unit in the College of Sciences and Technology at the University of Houston-Downtown, began with the mission of 
assisting science, technology, engineering, and mathematics (STEM) undergraduates to graduation with a STEM degree. Since this initial effort of organization, the SA has graduated over 1000 STEM undergraduates, most of whom are Hispanic and/or minority students. The longitudinal success of the initial effort became solidified by the development of a mentoring structure, but became extraordinary as a structure for supporting mentored research was solidified. This paper outlines the structure and function of creating a mentored research program for freshmen and sophomores. As with other institutions of higher education, mentored research is generally associated with the late junior and senior years and for the top five to ten percent only. UHD attempts to put into place a culture accepting of early career mentored research for freshmen and sophomore undergraduates, thereby offering increased experiential opportunities and exposure to students considering advanced degree study.

UHD is located only twenty minutes by rail to the world reknowned Texas Medical Center, MD Anderson Cancer Center, Baylor College of Medicine, McGovern Medical School UT School of Public Health, and UT Graduate School of Biomedical Sciences all within the fourth largest city in the United States. Only one hour by car finds NASA and the U.S. space program. One can easily gather that partnerships, internships, and research opportunities abound for the UHD undergraduate. These opportunistic collaborative partnerships and strong networking helped created graduate and medical school links for UHD undergraduates in addition to extracurricular exposure to top tier research laboratories, thus enhancing the work of UHD PhDs and their research.

\section{The Program Components}

The Scholars Academy (SA) is an academically competitive program in UHD's College of Science and Technology (CST) that promotes scholarship and a system of support for student success targeting qualifying STEM undergraduates (approximately 185-200 each semester). SA utilizes an established a multi-point STEM program of support yielding not only student success, but also offers a template for replication. Initially, the multi-point model included: Point 1: Scholarship Support assisting full -time student status; Point 2: Mentoring - PhD faculty and peer mentors; Point 3: Seminar/Field trips as broadening experiences and career enhancement; Point 4: Graduate School/Workforce Preparation in the form of CV and Personal Statement development; and Point 5: Exposure to In-house \& External Research/Internship opportunities. The SA program model also includes: Point 6JUMPSTART Research early summer workshop led by $\mathrm{PhD}$ researchers in the first two years of university; Point 7- Pre-College START early fall followed by a core seminar course creating a cohort group; Point 8- Research dissemination support; Point 9- Mentor (FM/PM) Training; and Point 10- GRE preparation workshops and access to online practice materials. 
An historical examination of five program components as delivered by the Scholars Academy will outline how this program supports advancement into graduate clinical and medical science success. Anecdotal information will provide qualitative insight into building pathways to advanced degrees in clinical, research, and medical areas. Later, with the award of several grant awards the multi-point program activities became condensed into five major categories supporting STEM undergraduates. Table 1 outlines the details of each category of support.

Table 1. Major Categories of Undergraduate STEM Support Creating a Pathway to Advanced Degree Study.

\begin{tabular}{ll}
\hline Mentoring & Discipline-based Small Learning Communities \\
Led by PhD Faculty Mentor & \\
Led by Trained Peer Mentor (upper division) & Networking Meetings monthly per semester (consist of \\
CV/resume/Personal Statement development; academic progress review; & study sessions) \\
Community Engagement Service Project (one per semester)
\end{tabular}

Career and Research

Skill Development

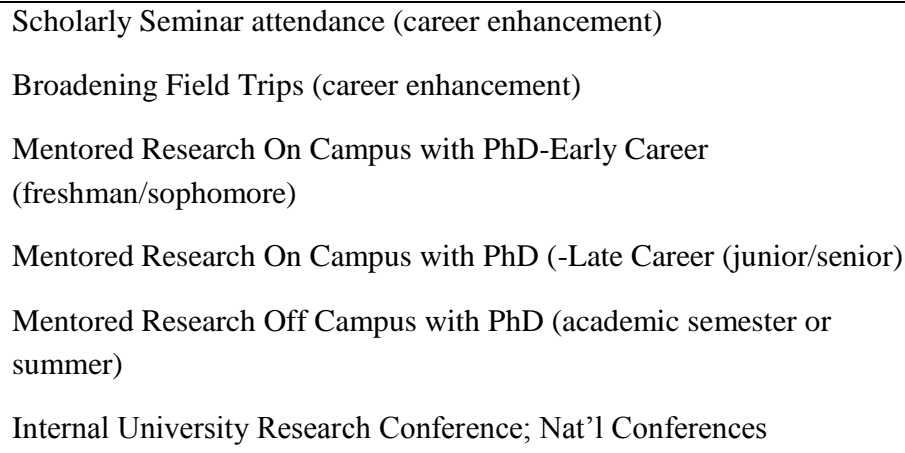

Of these multiple points of influence, anecdotal and quantitative data suggests mentored research experiences hold the major impact for any undergraduate, but particularly minorities to develop confidence, competence, and insight needed to entertain an advanced graduate or professional degree of study.

\section{The Infrastructure}

Using discipline-based groups small learning communities (SLCs) are formed to make up the Scholars Academy. The mentoring infrastructure is formed by 18 smaller learning communities representing the natural science, the computer science and engineering 
technology, and mathematics and statistics disciplines. The 18 small learning communities represent the largest number ever of SLCs. The SA mentoring communities did not become established in support of SA STEM undergraduates until the year 2000. With the evolution of SLCs a faculty member was employed as the peer mentor coordinator. This role was established to oversee the upper division peer mentor undergraduates selected and trained to assist the discipline-based faculty mentors. As the size of selected STEM undergraduates increased so too did the infrastructure of the mentoring groups (See the 2016 structure of mentoring image in Figure 1. Mentoring groups (SLCs) focus upon maintaining a limit on the number of mentees within the group. Ideal group membership numbers are evidenced to be between 10-12 members per mentoring group.

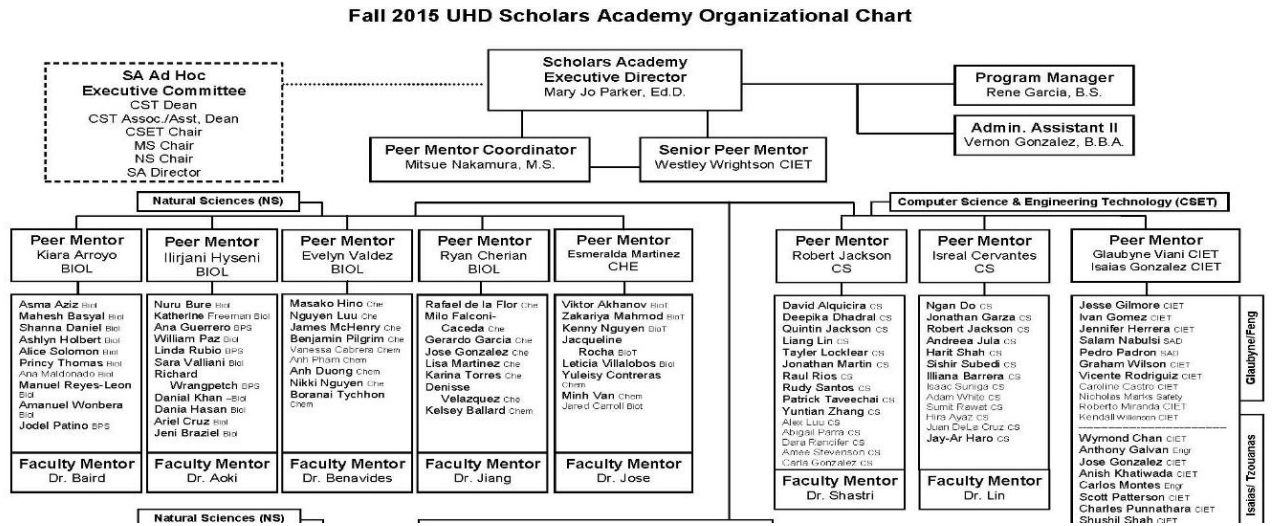

Figure 1. Scholars Academy organizational chart of discipline-based small learning communities.

Faculty mentors and peer mentors constitute the final pieces of the SLC infrastructure. The faculty mentor represents the expert near-peer (Ingebretson, A., Sjoberg, L., and Larson, S., 2014; Tenebaum, L., Anderson, M., Jett, M., and Yourick, D, 2014) relationship builder. Another leader of each SLC is the peer mentor representing the peer-to-peer relationship builder. Planned opportunities for faculty and peer mentors interactions occur throughout the semester on a monthly basis. These interactions target cognitive and non-cognitive learning such as personal skill development, social supports, formation of study groups, sharing notes and experiences about classes targeting academic strategies, thus giving purpose to the planned monthly network meetings. Most influential are the opportunities for role modeling successes across more than academics, such as career, gender, and ethnicity (Jacobi, 1991). Key to the infrastructure of mentoring is a student leader of peer mentors and a faculty leader over the peer mentors. Selected peer mentors meet monthly with the leadership to revisit common missteps, celebrate full participation in SLC activities, and share hints among the peer mentors that worked within their SLC so that these might be integrated into other groups. The Peer Mentor Coordinator takes on the role of supervisor and trainer, thereby maintaining the peer-to-peer role of the peer mentor. Of utmost 
importance is ensuring the peer mentors do not take on judgmental or supervisory roles within their groups or the peer-to-peer trust is likely lost. Peer mentors must be seen as peers to each SLC member, one who is taking also courses but through their own personal experiences in college is someone who can be trusted as SLC members seek advice, information, collegial friendship, and connections.

\subsection{Role of the Mentors}

The role of faculty mentors and peer mentors differ only in objectives. Faculty mentors aim to guide undergraduates in the development of cognitive and non-cognitive skillsets. Some of the skillsets include: 1) building academic skills, facilitate their success by inquiry (verbal-How are you doing in your courses; non-verbal- Noticing lack of attendance to courses, SLC meetings, and attitudinal changes in general) and 2) reward dedicated efforts and anticipated potential by inviting them to join research labs currently or in the future. Faculty mentors actively support relationship building activities through listening to the undergraduates, making time to meet with them, and suggesting their attendance to a seminar or study session. Peer mentors also aim to guide peer undergraduates, but rely heavily on social, behavioral, and recreational activities and supports to build relationships with SLC undergraduates. They do realize the role includes giving advice, being a trustworthy shoulder to lean on, and role modeling success which is especially impactful for minority and first generation undergraduates (Pita, Ramirez, Joacin, Prentice, \& Clarke, 2013). These faculty members agreed in 1999 to participate in the Scholars Academy program as mentors of peer groups and research mentors for no reimbursement, but rather for the good of the students they served. By this time in 1999, research data was abounding indicating that minority and underrepresented undergraduates were not performing as well as non-minority counterparts, nor completing science, technology, engineering, and mathematics (STEM) degrees (Dennis, Phinney, \& Chuateco, 2005; Freeman, 2009;). This was the beginning of the Scholars Academy, initiated by faculty who understood the importance of mentored research as a vehicle to understanding what a clinical or medical terminal degree of study could look like and knew how to open doors of accessibility for these undergraduates.

\subsection{Broadening Experiences Influential to Career Pathways}

The need for enhancement and broadened understanding of careers in STEM is a critical component to finding the pathway to advanced clinical and medical pathways for the first generation undergraduate. Because no familial background exists of the myriad of careers across STEM for the first generation undergraduate and the minority student except for medical doctors and perhaps dentists as a result of familial visits, providing enhanced field trips to graduate schools and medical programs must occur to open their eyes to the world of STEM. Further, scholarly seminars by renowned scholars, practitioners and by SA 
Alumni who have completed their terminal $\mathrm{PhDs}$ and $\mathrm{MDs}$ makes such a profound difference for these undergraduates. They see "themselves" in the successful alumni brought back due to "share their story"! SA Alumni are invited to present at the Student Research Conference.

\subsection{Creating Important Traditions}

Student Research Conference - An Internal Demonstration of Research - This return of successful (and terminally complete) alumni began in year three of the Scholars Academy organization. It was not until year seven that several alumni members had actually completed medical and/or clinical degrees. This began the tradition of keynote speakers as a major part of the spring student research conference! The tradition continues today in 2018 with an expansive cast of clinical and medical professionals forming the selection pool. Table 2 outline the tremendous pathways which has been built and which continue to benefit the emerging undergraduates as they enter the pathway. Establishing the Graduate School and Internship Fair - Bringing Partners to the Table - In the second year of the Scholars Academy an opportunity to invite current and potentially future partners to the UHD campus was implemented. Originally the focal partners consisted of graduate and professional schools from the Texas Medical Center, other tier-one institutions producing doctoral degrees, and nationally well-known institutions educating medical, doctoral, pharmacy, veterinarian, nursing, and dental terminal degrees. This event actually supported mutually beneficial goals. Goal one focused on these institutions having access to underrepresented high-performing undergraduates for the purposes of recruitment to their post-baccalaureate institutions, recruitment to internship/summer research programs funded within labs at these institutions, and promoting face-to-face interactions of recruitment officers with undergraduates in one locale with a guaranteed audience of approximately 200 or more. Goal two found the undergraduates being trained to interact with graduate and industry recruitment representatives, improvement in professional dress codes and behavior associated with graduate and industry representatives, and allowing the undergraduates to have first opportunities with many summer or academic research opportunities. Key Federal Grant Awards Supporting Mentored Research - The UHD Scholars Academy has a stellar record of ongoing federal and other awarded grant projects. Some \$15 million were written and awarded in the first ten years, including the Army Research Office, Minority Access to Research Communities, and the Department of Education Minority Serving Engineering Improvement Program. These funded programs contained elements of the SA success components in particular partnerships with graduate or medical center research laboratory research opportunities with stipend support. During the second decade of the SA, over $\$ 10$ million continued the earlier initiated mentored research opportunities. However, after the first five years, partners began requesting SA administration to support their federal grant proposals which would utilize the successes of the academic unit as well as 
include support for underrepresented undergraduates which assisted in providing additional opportunities for SA undergraduates. Mentored research, funded or unfunded, assisted a culture of looking beyond the bachelor's degree to the next step or to enter into a graduate or professional terminal degree (Lopatto, 2004; 2007). When undergraduates hear, see, and have the opportunity to interact with others like themselves about how each achieved their successes, they begin to envision the possibilities for themselves as a collective and as individuals (Refer to Table 2.).

Table 2. Recent Data Depicting Increases in Entrance into Advanced

Education Pathways - 2015-2018.

\begin{tabular}{cccc}
\hline Time Period & PhDs & MD & PA/Pharm/ DDS/DVM \\
\hline $1999-2018$ (18 years) & 60 & 64 & 28 \\
$2015-2018$ (3 years) & 22 & 22 & \\
$2017-2018 \quad$ (15-months) & 8 & 3 & \\
\hline
\end{tabular}

\section{References}

Dennis, J., Phinney, J. and Chuateco, L. (2005). The Role of Motivation, Parental Support, and Peer Support in the Academic Success of Ethnic Minority First Generation College Students. Journal of College Student Development, v46 n3 p 223-236.

Freeman, S. (2009). Effective Mentoring. IFLA, v35 n2, p. 171-182.

Ingebretson, A., Sjoberg, L., and Larson, S. (2014). An Undergraduate Research Experience: From Research Methods to the Institutional Repository. PURM. Retrieved at blogs.elon.edu/purm/files/2014/04/Ingebretson-et-al-PURM-3-2-final1.pdf.

Jacobi, M. (1991). Mentoring and Undergraduate Academic Success: A Literature Review. Review of Educational Research, v 61 n 4 p505-532.

Kotkin, J. (2010). The Changing Demographics of America. Smithsonian Magazine. Retrieved on November 6, 2018 at https://www.smithsonianmag.com/travel/thehanging-demographics-of-america 538284/

Lopatti, D. (2004). Survey of Undergraduate Research Experiences (SURE): first findings. Cell Biology Education. Vol. 3, 270-277.

Lopatti, D. (2007). Undergraduate Research Experiences Support Science Career Decisions and Active Learning. CBE - Life Sciences Education. Vol. 6, 297-306.

Shrestha, L. and Heisler, E. (2011). The Changing Demographics of the United States. Congressional Research Service. Retrieved on November 6, 2018 at https://fas.org/sgp/crs/misc/RL32701.pdf.

Tenebaum, L., Anderson, M. Jett, M. and Yourick, D. (2014). An innovative Near-Peer Mentoring Model for Undergraduate and Secondary Students: STEM Focus. Innovative Higher Education, v39 n5 p37u5-385. 